\title{
Estudio Antracológico en la Alta Cordillera Mendocina (Argentina): El Caso del Sitio El Indígeno y sus Implicancias A Nivel Macro-Regional
}

\author{
Anthracological Study in the High Mountains of Mendoza (Argentina): The Case of the \\ El Indigeno site and its Implications at a Macro-Regional Level
}

Diego Andreoni ${ }^{i}$

\section{RESUMEN}

Se presenta el análisis antracológico del sitio El Indígeno (Mendoza-Argentina), localizado a $3300 \mathrm{msnm}$, en ambiente Altoandino. El principal objetivo es estimar los criterios que intervinieron en la gestión de recursos leñosos, en ambientes con baja oferta ambiental y con elevada demanda social. En segundo lugar, aportar nuevas variables que permitan enriquecer el conocimiento que se tiene del sitio y sus implicancias para la arqueología del Centro Oeste Argentino y de Chile Central. Se identificó un total de 14 taxa. Las variaciones en las frecuencias y las distintas procedencias de los mismos, permitieron observar que en un primer momento se utilizaron taxa locales y que, paulatinamente en el tiempo, se habrían incorporado otros que proceden de pisos ecológicos inferiores de la vertiente occidental de los Andes, así como géneros que crecen más distantes a ambos lados de la cordillera. Las asociaciones vegetales identificadas en el sitio permiten concluir que la leña utilizada procede mayormente de Chile, lo cual soportaría la idea de que El Indígeno formó parte de un circuito de circulación de grupos cazadores recolectores del Periodo Alfarero Temprano de Chile Central.

Palabras claves: Antracología, Leña, Centro Oeste Argentino, Chile Central

\section{ABSTRACT}

This paper presents the anthracological analysis of El Indígeno site (Mendoza-Argentina), located at $3300 \mathrm{~m}$ asl, within an Altoandino environment. The main objective is to estimate which criteria intervened in the management of woody resources in environments with low supply and a high social demand of this resource. Secondly we intend to provide new variables which allow increase knowledge about the site and its implications for the archeology of the Center West Argentina and Central Chile. A total of I 4 taxa were identified.Variations in the frequency and the different origins of the taxa allow observeing that, at first, local taxa were used, and gradually genera of lower ecological zones and of remote regions on the both sites of the Andean mountains are incorporated. Plant associations identified on the site permit to conclude that firewood used comes mainly from Chile, which supports the idea that El Indígeno site was part of a circulation circuit of hunter-gatherers groups during the Early Ceramic Period of Central Chile.

Keywords:Anthracology, Firewood, Central West Argentino,Central Chile

i División de Arqueología Museo de La Plata FCN y M Paseo del Bosque S/N La Plata CP 1900, Argentina. Correo-e: andreondieg@ hotmail.com 


\section{INTRODUCCIÓN}

Desde su descubrimiento, en la década de 1970, el sitio arqueológico El Indígeno ha despertado múltiples incógnitas en la arqueología del Centro Oeste Argentino (COA) y de Chile Central (Cornejo y Sanhueza 2003,20 I I a y b; Durán et al.2006; Lagiglia 1975, 1997; Lagiglia et al. 1994; Neme 2007; Neme y Gil 20 I 3; Sanhueza et al. 2004). Son varios los aspectos que lo diferencian del resto de los sitios de la región, entre éstos podemos considerar su ubicación a 3300 msnm, las dimensiones del sitio, la concentración de recintos o estructuras y las particularidades del registro cerámico. Este último está caracterizado por una elevada cantidad de fragmentos, así como por la presencia de ollas y escudillas completas. Se destaca que una parte importante del mismo se corresponde con complejos culturales de Chile Central (Lagiglia 1997, Neme 2007, Sanhueza et al. 2004). Los estudios arqueológicos que sucedieron al descubrimiento del sitio han propuesto distintas hipótesis sobre su funcionalidad y sus implicancias a nivel regional. En este sentido, un aspecto que genera controversia es la procedencia de las poblaciones que lo ocuparon. Lagiglia (1997) considera que El Indígeno formó parte de circuitos regulares de trashumancia entre ambas vertientes de la Cordillera de Los Andes, donde los cazadores recolectores del sur de Mendoza intercambiaban productos con las poblaciones agroalfareras de los valles de Chile Central (Lagiglia 1997). Una segunda propuesta es la realizada por Neme (2007), quien interpreta que las ocupaciones de la Alta Cordillera reflejarían procesos de intensificación regionales sucedidos ca 2200 años AP. Según este modelo, los ambientes de altura pueden ser definidos como "marginales" y su ocupación se daría cuando otros ambientes con mayor productividad (i.e. valles intermedios) se vieron saturados por el incremento en la densidad poblacional (Neme 2007). Desde esta perspectiva el surgimiento de Aldeas de Altura, tal como Neme (2007) define a El Indígeno, permitiría a las poblaciones de cazadores recolectores ampliar los rangos de acción e interacción, ocupando nuevos pisos ecológicos que hasta el momento estaban inhabitados.

El estilo cerámico mejor representado en El Indígeno es el Overo, el cual es definido por Lagiglia (I997) como de tipo utilitario, característico de grupos cazadores recolectores móviles que ocuparon sitios de altura y que mantuvieron un fluido contacto con grupos provenientes de la vertiente occidental de Los Andes. Sanhueza et al. (2004) han realizado estudios tecnológicos y estilísticos específicos sobre este tipo de material cerámico con el fin de evaluar su procedencia. Los resultados indican que las características formales y tecnológicas de la cerámica Overa presentan atributos que se corresponden al complejo cultural Llolleo de Chile Central (Sanhueza et al. 2004). A partir de las características tecnológicas del material lítico, los estilos cerámicos, la localización y el tipo de asentamiento, Cornejo y Sanhueza (2003, 20 I I a y b) realizan una tercer propuesta sobre la procedencia de las poblaciones que ocuparon El Indígeno. Consideran que este sitio formó parte de los circuitos de circulación de grupos cazadores recolectores del Periodo Alfarero Temprano (PAT) de Chile Central, el cual se extiende desde los 300 años aC hasta los $1000 \mathrm{dC}$. Durante este periodo coexistieron en el Centro de Chile tres grupos, definidos sobre la base de los estilos cerámicos, las prácticas funerarias, la dieta y los patrones de asentamiento. Dos fueron comunidades semi-sedentarias, que practicaban la horticultura y producían una cerámica denominada Bato y Llolleo; mientras que el tercero estuvo representado por cazadores recolectores móviles, asentados principalmente en la zona de montaña, que utilizaban un número más acotado de cerámica con respecto a los primeros. Cerca de los 1000 años $\mathrm{dC}$ se producen cambios en la organización socio-económica surgiendo en esta región la denominada cultura Aconcagua, característica del Periodo Intermedio Tardío (PIT), sociedad con una mayor dependencia de la agricultura, que domina la mayor parte de la zona de valles y que desplaza a los cazadores recolectores a la cuenca alta y valles interandinos (Cornejo y Sanhueza 2003, 20 I la).

Con el desarrollo del presente trabajo nos proponemos aportar nuevos elementos que permitan enriquecer el conocimiento que se tiene sobre El Indígeno, en particular a través del análisis de su registro antracológico dentro del marco de la arqueología del COA y de Chile Central, para finalmente retomar en la discusión las ideas expuestas previamente sobre su ocupación. $\mathrm{Si}$ consideramos la localización del sitio en la Alta Cordillera, región que se caracteriza por una baja oferta ambiental de especies leñosas, clima frío y seco, 
con heladas durante todo el año y fuertes nevadas invernales, con condiciones climáticas de tipo glaciar y peri-glaciar (Capitanelli 2005), sumado a la elevada concentración de estructuras arquitectónicas (si bien no consideramos que su ocupación fuera absolutamente sincrónica), podemos inferir que la demanda de recursos combustibles debió ser elevada durante los meses que se ocupó el sitio, y que la oferta ambiental fue relativamente baja. En este contexto, el análisis antracológico de El Indígeno resulta adecuado para evaluar cómo se llevó a cabo la gestión de un recurso crítico e imprescindible como es la leña. En el presente trabajo entendemos la gestión de los recursos leñosos como un modo de actuación históricamente construido, que se halla en relación a las estrategias generales de abastecimiento de otros recursos (i.e. líticos, faunísticos, tecnológicos en general) (Pique í Huerta 1999). En este sentido las estrategias de aprovisionamiento de leña están socialmente establecidas y tienden a satisfacer la demanda del grupo, la cual será mayor o menor según sea el tipo de asentamiento, la duración de las ocupaciones y el tamaño del grupo, entre otros aspectos (Marconetto 2005, Pique í Huerta 1999). Por lo anterior, las estrategias de obtención de madera para leña serán diversas según sea la relación entre la oferta o disponibilidad ambiental, las necesidades sociales (demanda) y la capacidad técnica del grupo para resolverlas.

Entendemos que la presencia de un taxon no es criterio suficiente para considerar que el mismo será utilizado como leña, sino que lo que determina su disponibilidad es el reconocimiento de la sociedad de que ciertas especies pueden ser utilizadas como leña. El proceso de selección de los recursos leñosos consiste en discriminar, entre una variedad de plantas, cuáles son las más adecuadas para realizar diferentes tareas. La realización de distintas actividades orientadas a satisfacer las necesidades del grupo determina la demanda de combustibles. Por lo cual, la demanda determinará en última instancia, el tipo de madera a ser seleccionada, la intensidad y rangos de recolección, junto con la inversión de tiempo y energía destinada en la obtención (Pique í Huerta 1999). Ahora bien la demanda de recursos combustibles está limitada por la oferta del ambiente. En el caso de las sociedades que no intervienen en la reproducción de los recursos, como son los cazadores recolectores, la oferta de combustibles está vinculada a los ciclos naturales. En este tipo de sociedades la gestión de recursos leñosos se realiza a través del conocimiento de las propiedades de los taxa que conforman las distintas comunidades vegetales, los ritmos de producción de madera muerta y de regeneración, así como la potencial aplicación de algunos taxa en otras actividades del grupo (i.e. alimentación, medicina, tecnología, entre otras). Habitualmente se supone que la recolección de leña se orienta principalmente a la selección de madera muerta. Sin embargo, el ciclo de producción de madera muerta puede ser superado por los ritmos de recolección de leña según sea la duración de la ocupación, la frecuencia y la intensidad de las combustiones (Marconetto 2005, Pique í Huerta 1999). Desde esta perspectiva teórica es que nos proponemos como principal objetivo establecer los criterios que intervinieron en la selección de recursos combustibles en la Alta Cordillera y conocer cómo la oferta ambiental y la demanda social del recurso influenciaron los procesos de gestión, selección y utilización de leña en este ambiente.

Los estudios antracológicos en el COA comienzan con los trabajos realizados en el norte de Mendoza en sitios incaicos del valle de Uspallata (Garibotti 1998, 1999-2000, Roig y Bárcena 1997). En el Sur de Mendoza hemos desarrollado recientemente un proyecto sistemático de estudio de material leñoso carbonizado para el cual se realizó una colección de referencia de más de 40 especies que crecen en la región o en áreas vecinas (Andreoni 2010, 2014) y se llevaron a cabo aproximaciones experimentales sobre las propiedades combustibles de las maderas (Andreoni et al.20l I,Andreoni 20l4). Estos trabajos nos han permitido realizar el análisis antracológico de distintos sitios emplazados en diferentes provincias fitogeográficas. Por ejemplo, en Patagonia se estudió Arroyo Malo 3 y El Mallín; en el Monte, Agua de los Caballos I; y en ambientes ecotonales entre Monte y Patagonia, la Gruta de El Manzano (Figura Ia) (Andreoni 20I4, 20I5, Andreoni y Capparelli 2012, Llano y Andreoni 2012). Estos estudios nos han permitido caracterizar el registro antracológico de la región durante los últimos 8900 años AP y evaluar procesos culturales que, hasta el momento, habían sido abordados desde otros materiales del registro arqueológico (i.e. arqueofaunísticos, líticos, carpológicos y cerámicos). Por ejemplo, se ha reconocido en algunos de 
estos sitios el acontecimiento de procesos de intensificación (Andreoni 2014, 2015, Andreoni y Capparelli 20 I2, Llano y Andreoni 20I2). El Indígeno, sitio abordado en el presente trabajo, constituye el de mayor altitud estudiado para la región del COA y el único situado en la provincia fitogeográfica Altoandina.

\section{ÁREA DE ESTUDIOY ANTECEDENTES ARQUEOLÓGICOS DE EL INDÍGENO}

El Indígeno se encuentra ubicado a los $34^{\circ} 30^{\prime}$ 08” S y 69० 59' I4" W, a 3300 msnm en la Cordillera de Los Andes (Figura la). Fitogeográficamente se ubica en la Provincia Altoandina, distrito cuyano, el cual se extiende desde los 2200 a los 4500 msnm (Cabrera 1976). La comunidad vegetal dominante es la estepa de gramíneas, principalmente de especies de Stipa spp., Festuca spp. y Poa spp. En las laderas se desarrollan especies arbustivas como Adesmia pinifollia, asociadas con Ephedra andina, Berberis empetrifolia, Senecio uspallatensis, entre otras. Otras veces predomina $A$. obovata asociada con Mulinum ovalleanum. En las cumbres hay arbustos o sufrútices en cojín o formando placas contra el suelo, como Adesmia subterranea, Nassauvia lagascae, entre otras. Mientras que en las vegas altoandinas predomina Andesia bisexualis, acompañada por Plantago barbata, Senecio breviscapus, entre otras (Cabrera 1976). Por debajo de los 2200 msnm y del lado oriental de la cordillera, se desarrolla una vegetación arbustiva de tipo Patagónica, donde además de los taxa mencionados para las laderas, se registran otros tales como Colliguaja intergerrima, Anarthrophyllum rigidum, Chuquiraga oppositifolia, Ochetophilla trinervis, entre otros.

Por otro lado, en la vertiente occidental de la cordillera, representada por los valles centrales de Chile, las condiciones fitogeográficas son muy diferentes. Las lluvias provenientes del océano Pacifico son retenidas por la Cordillera de Los Andes, lo cual genera un mayor régimen de precipitación y favorece el desarrollo de una vegetación de tipo mediterráneo, con un importante número de endemismos (Muñoz-Schick et al. 2000). Considerando las diferencias topográficas, los sustratos heterogéneos, la orientación de los valles y la exposición a la precipitación oceánica, se pueden

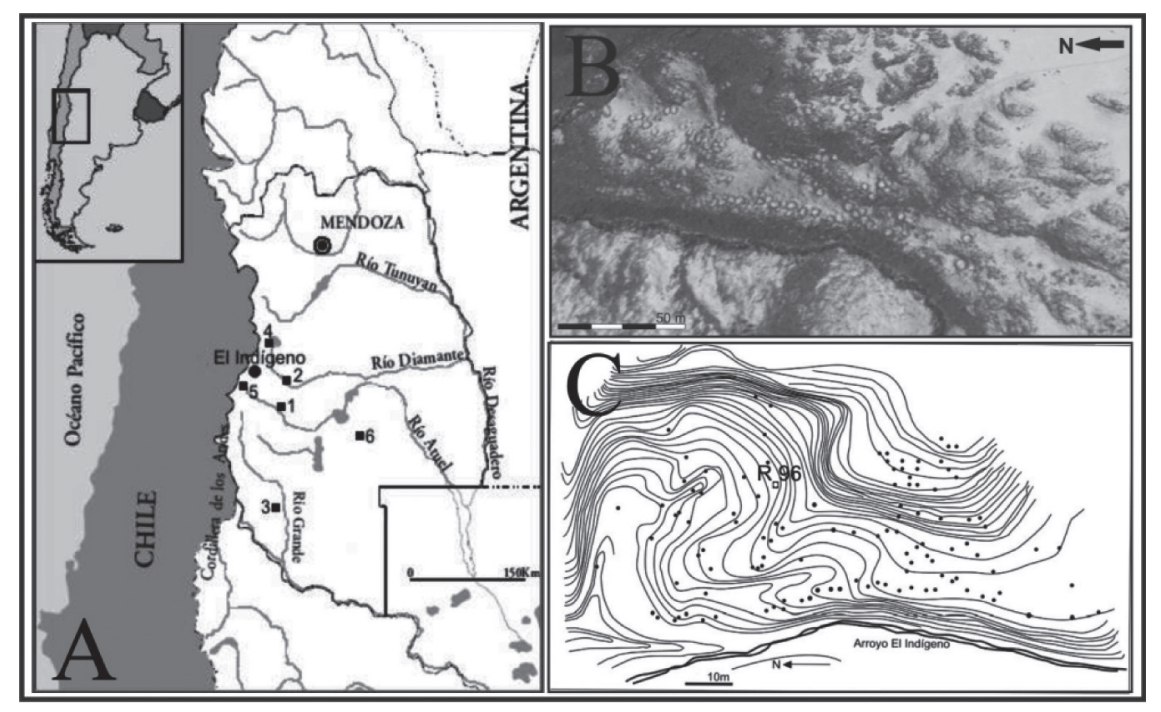

Figura 1: A) Mapa mostrando la localización de El Indígeno y los sitios mencionados en el presente trabajo: 1) Arroyo Malo 3, 2) El Mallín, 3) Gruta de El Manzano, 4) Laguna El Diamante, 5) Los Peuquenes, 6) Agua de los Caballos 1; B) imagen satelital de El Indígeno; C) Plano del sitio El Indígeno mostrado la disposición de las estructuras habitacionales, el arroyo y las curvas de nivel (modificado de Neme 2007).

Figure 1: A) Map showing the location of El Indigeno and the sites mentioned in this paper 1) Arroyo Malo 3, 2) El Mallín, 3) Gruta de El Manzano, 4) Laguna El Diamante, 5) Los Peuquenes, 6) Agua de los Caballos 1; B) satellite image of El Indigeno; C) El Indígeno site plan shown the disposition of residential structures, the creek and the contour lines (modified from Neme 2007). 
diferenciar según el gradiente altitudinal distintas unidades fitogeográficas (Muñoz-Schick et al. 2000): a) Matorral Esclerófilo: (I000 a I500 msnm) consiste en un matorral arborescente, dominado por Quillaja saponaria, Lithrea caustica y Kageneckia oblonga, en este piso se desarrollan en laderas otras especies arbóreas como Cryptocaya alba, mientras que en las zonas más abiertas aparece Acacia caven; b) Matorral subandino: (I500 a 2000 msnm), esta unidad es dominada por Kageneckia angustifolia, Guindilia trinervis y Colliguaja intergerrima, en las quebradas y afloramientos se encuentran bosquetes densos de Escallonia myrtoidea; c) Matorral Andino (2000 a 2700 msnm): matorral bajo dominado por especies arbustivas tales como Ephedra chilensis, Mulinum spinosum, Tretaglochin alatu, entre otras. Aquí se destaca un importante número de especies en común con el sur de Mendoza, entre éstas Adesmia piniffolia, A. obovata, Berberis empetrifolia, Chuquiraga oppositifolia; d) Estepa Altoandina (2700 a $3300 \mathrm{msnm}$ ): vegetación abierta que se caracteriza por la presencia de gramíneas, tales como Poa holciformis y Hordeum comosum, de plantas en cojín, (i.e. Laretia acaulis), y de arbustos de Adesmia aegicera; e) Desierto Altoandino (sobre los 3300 msnm): está compuesto por plantas en cojín, gramíneas cespitosas y hierbas en roceta; las especies más comunes son Oxalis spp, Nastanthus spathulata y Azorella trifurcata, entre otras.

Específicamente El Indígeno se encuentra emplazado en una vega cordillerana sobre el piso de un valle intermontano, próximo a los pasos cordilleranos de Las Leñas, Borbollón y Las Lágrimas. El asentamiento está ubicado sobre una colada basáltica paralela al arroyo El Indígeno. En el lugar se relevó un total de 126 recintos, cuyas dimensiones varían entre I,5 m y $12 \mathrm{~m}$ de largo y 0,50 a I m de altura. El conjunto total abarca una superficie de $10.000 \mathrm{~m}^{2}$ aproximadamente (Figura Ib). Los recintos han sido construidos con las rocas de la colada y son básicamente de dos tipos: circulares o semicirculares y rectangulares.

La primera campaña arqueológica se realizó en 1990 a cargo de H. Lagiglia. Durante la misma se levantó un mapa y se numeraron las pircas. En esta ocasión se excavaron cuatro recintos circulares, en el recinto 52 se realizó un fechado sobre carbón del nivel $2(15-30 \mathrm{~cm})$, que dio una fecha de $980 \pm 90$ años ${ }^{14} \mathrm{C} \mathrm{AP}$ (Lagiglia et al. 1994) (Tabla I). La segunda campaña fue realizada en 1994, a cargo de G. Neme. Durante ésta se realizó un muestreo superficial sistemático y se relevó con teodolito el asentamiento. Como resultado, se confeccionó un plano que incluye la topografía del terreno (Figura Ic). Se realizaron prospecciones en las inmediaciones del sitio, lo cual permitió reconocer tres nuevos asentamientos pircados, de pequeñas dimensiones, sumando un total de siete pircas más. Además fue posible ubicar dos potenciales fuentes de leña. En la segunda campaña se excavó un recinto rectangular $\left(\mathrm{N}^{\circ} 96\right)$ y se realizaron nuevos fechados radiocarbónicos (Neme 2007) (Tabla I).

Sobre la base del registro arqueológico superficial, las dataciones radiocarbónicas, el estado de conservación y altura de las pircas, el enterramiento de los materiales en distintos sondeos, la cerámica chilena asociada y la meteorización del material óseo, se subdividió el sitio en dos sectores; Norte y Sur (Lagiglia 1997 y Neme 2007). Toda esta información permitió considerar que el sector Norte es más antiguo ( $1.470 \pm 60$ y $840 \pm 60$ años $\left.{ }^{14} \mathrm{C} \mathrm{AP}\right)$, está asociado a cerámica de tipo Llolleo de Chile Central y posee una mala conservación de las estructuras

\begin{tabular}{|c|c|c|c|c|c|c|}
\hline Recinto & Cuadricula & Nivel & Fecha ${ }^{14} \mathbf{C}$ & $\begin{array}{c}\text { Código de } \\
\text { Laboratorio }\end{array}$ & $\begin{array}{c}\text { Material } \\
\text { Fechado }\end{array}$ & Referencias \\
\hline I7 & - & 2 & $980 \pm 90$ & LP-430 & Carbón & Lagiglia et al. 1994 \\
\hline 96 & B2 & 4 & $840 \pm 60$ & LP-6II & Carbón & Neme 2007 \\
\hline 96 & B2 & 6 & $1.170 \pm 60$ & LP-573 & Carbón & Neme 2007 \\
\hline 96 & B2 & 9 & $1.045 \pm 45$ & AA-26I92 & Marlo de maíz & Neme 2007 \\
\hline 96 & B2 & II & $1.470 \pm 60$ & LP-562 & Carbón & Neme 2007 \\
\hline
\end{tabular}

Tabla 1: Fechados absolutos del sitio El Indígeno

Table 1: Dates of El Indígeno site 
pircadas. En cuanto al Sector Sur, se corresponde con los momentos más tardíos del anterior $(980 \pm 90$ años ${ }^{14} \mathrm{CAP}$ ), las pircas presentan un buen estado de conservación y se ha recuperado material cerámico de tipo Aconcagua de Chile Central (Neme 2007). La suma, a los fechados radiocarbónicos, de los indicadores estilísticos y la presencia de elementos hispánicos, han llevado a suponer que las ocupaciones del sitio se sucedieron con pocas interrupciones hasta momentos históricos (Neme 2007).

De las cuatro pircas excavadas hasta el momento, en el presente trabajo nos ocuparemos del registro antracológico de la única estructura rectangular ( $\mathrm{N}^{\circ}$ 96). Ésta tiene la abertura orientada al SE, sus dimensiones son $12 \mathrm{~m}$ de largo por $3 \mathrm{~m}$ de ancho. La pirca fue dividida en 12 cuadrículas (Figura 2), de éstas solo se excavaron dos: Al ( $1 \mathrm{~m}$ x I m) y B2 (2 m x $2 \mathrm{~m})$; la excavación se realizó siguiendo niveles artificiales de $5 \mathrm{~cm}$ de espesor; en la cuadricula Al se alcanzó una profundidad de 45 $\mathrm{cm}$ y en la cuadricula B2 de $65 \mathrm{~cm}$, en ambos casos las profundidades máximas se corresponden a los niveles donde se recuperó material arqueológico (Neme 2007). El análisis antracológico se realizó únicamente en la cuadrícula B2, ya que fue la única en donde se recuperaron carbones.

El conjunto arqueológico recuperado en El Indígeno es muy variado e incluye estilos cerámicos

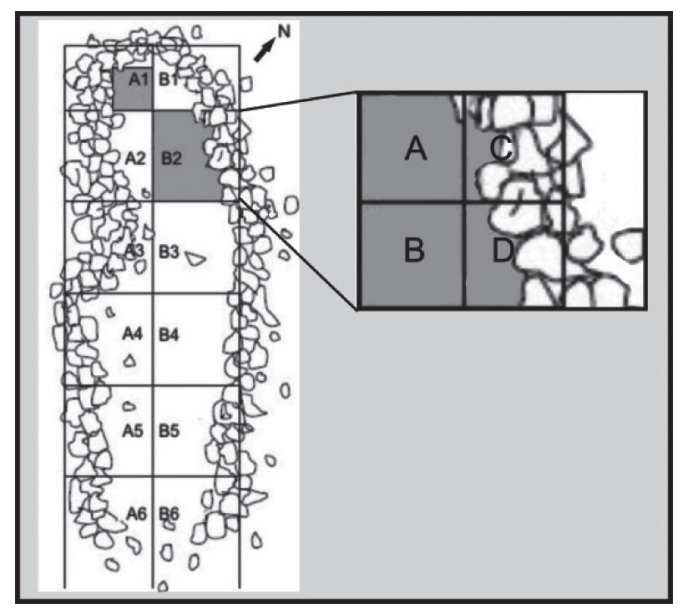

Figura 2: Recinto número 96 y detalle de la cuadricula B2 donde se aprecian los cuatro sectores excavados (modificado de Neme 2007).

Figure 2: Enclosure number 96 and B2 detail grid where excavated four sectors are appreciated (modified from de Neme 2007). locales y exóticos, instrumentos de molienda (molinos y manos), restos vegetales, carbones, productos de talla, restos arqueofaunísticos y adornos personales (i.e. tembetá y cuentas de collar) (Lagiglia 1997, Neme 2007). El material zooarqueológico es escaso y presenta un alto grado de meteorización y fragmentación. No obstante ello, se evidencia que el guanaco (Lama guanicoe) es el taxon mejor representado, además se identificaron restos de aves (probablemente Chloephaga melanoptera) y mamíferos pequeños y grandes indeterminados (Neme 2007). El material carpológico identificado hasta el momento es de particular interés ya que se trata de un fragmento de Lagenaria (Lagiglia et al. 1994), un grano y un marlo de maíz (Zea mays). El ambiente del sitio no es favorable al crecimiento de ninguna de estas especies, que podrían provenir de Chile o de la planicie oriental mendocina, regiones con un importante registro de estos cultivos (Lagiglia 1997; Neme 2007). Lamentablemente, si bien se menciona en Neme (2007) la presencia de otros escasos restos vegetales (no se especifica qué tipo de restos son), los mismos no han sido determinados al momento de presentar este manuscrito. El material lítico se caracteriza por un predominio de microlascas y ultramicrolascas con una gran diversidad de materias primas, muchas de las cuales pueden ser obtenidas en el arroyo El Indígeno. La presencia de desechos de talla de obsidiana, principalmente en los niveles inferiores, parece estar indicando la conservación de los artefactos confeccionados sobre esta materia prima que no se encuentra disponible en las proximidades del sitio. Un patrón similar puede inferirse para aquellas realizadas en sílice. Los estudios geoquímicos para determinar procedencia de la obsidiana señalan, sobre un total de tres muestras, que una procede de la cantera de Las Cargas (aproximadamente 90 $\mathrm{km}$ del sitio) mientras que las restantes proceden de alguna fuente de obsidiana aún no determinada (Giesso et al. 20II).

Entre los estilos cerámicos hallados en el sitio (i.e. Overo, Marrón Pulido, Negro Pulido y Pintada entre otros) el mejor representado es el denominado estilo Overo, el que como mencionamos tiene una gran afinidad tecnológica con la alfarería del Complejo Llolleo del Periodo Alfarero Temprano de Chile Central (Sanhueza et al. 2004). Asimismo, se han recuperado en superficie (Lagiglia 1997) 
y en estratigrafía (Neme 2007) tipos cerámicos correspondientes al Periodo Intermedio Tardío de Chile Central como Aconcagua Salmón y Diaguita Chileno.

A partir de los fechados radiocarbónicos y los tipos cerámicos, Lagiglia (1997) definió al menos cuatro ocupaciones del sitio: la primera ocupación se corresponde con el material Llolleo y está fechada ca 1400 años ${ }^{14} \mathrm{C}$ AP (en el recinto 96 abarca desde la base hasta el nivel 5). La segunda ocupación se corresponde con el Periodo Intermedio Tardío en Chile Central fechada en ca 980 años ${ }^{14} \mathrm{C}$ AP (en el recinto 96 desde el nivel 4 a la superficie). La tercera y cuarta se corresponden con los hallazgos superficiales, entre éstos se registran fragmentos cerámicos diaguita chileno y materiales poscontacto entre los que se incluyen cuentas de vidrio y monedas del siglo XIX de origen chileno. De las cuatro ocupaciones propuestas por Lagiglia (1997), en el recinto 96 se encuentran representadas las dos primeras (Neme 2007).

\section{MATERIALESY MÉTODOS}

\section{Muestras de referencia}

Para llevar a cabo la identificación de los restos antracológicos se utilizó una metodología estándar (Solari 1993, Pique i Huerta 1999, Marconetto 2005, Andreoni 2014, entre otros). En primer lugar, se elaboró una colección de referencia del área de estudio, se colectaron muestras de herbario, se obtuvieron muestras de tallos y raíces. Luego se realizaron cortes delgados en los tres planos de observación de la madera y se realizaron las descripciones anatómicas correspondientes. Durante el proceso de carbonización se producen modificaciones en las dimensiones de los distintos tipos celulares, no obstante, los rasgos cualitativos se mantienen constantes (Andreoni et al. 20II, Marconetto 2005, Pique i Huerta 1999, Solari 1993, Smart y Hoffman 1988), por este motivo las descripciones anatómicas se realizaron siguiendo los criterios cualitativos de IAWA (1989). La mayoría de las descripciones anatómicas de los taxa aquí tratados han sido publicadas previamente (ver Andreoni 2010, Andreoni y Capparelli 20I2). No obstante, se tuvo que recurrir a descripciones realizada por otros autores, a la página web de la IAWA (Inside Wood 20I3), en algunos casos a bibliografía específicos de Chile (Rancusi et al. 1987, Solari 1993) y Argentina (Tortorelli 2009). Por ejemplo, para las descripciones anatómicas de Cryptocarya alba y Maytenus boaria (Rancusi et al. 1987; Solari 1993; Tortorelli 2009),y de Dasyphyllum diacanthoides (Tortorelli 2009); mientras que Escallonia fue comparada con las descripciones de E. myrtilloides (Inside Wood 20 I3, Rallo et al. 2008) y E. illinita, E. pulverulenta, E. rubra, E. serrata (Solari 1993). En cuanto a la determinación de Nothofagus cf. leoni, hemos comparado los carbones arqueológicos con distintos representantes del género Nothofagus (N. alessandri, N. antartica, N. glauca, N. oblicua, N. procera, N. pumilla, N. betuloide, N. dombeyi y N. nitida) brindados por Rancusi et al. (1987), Rivera (1988), Solari (1993) y Tortorelli (2009). Además de estos taxa se consideró la posibilidad de que la leña utilizada en El Indígeno se correspondiera con distintos tipos de yaretas o plantas en cojín (i.e Azorella spp, Mulinun spp., entre otras), las cuales son actualmente utilizadas por los puesteros en la cordillera. En la Tabla 2 se expone la Clave Dicotómica utilizada para el análisis antracológico de El Indígeno.

\section{Muestras antracológicas}

Durante la excavación la cuadrícula B2 fue dividida en cuatro sectores ( $A, B, C$ y $D)$. Dada la elevada cantidad de carbones recuperados se decidió trabajar con un sector de cada nivel arqueológico. En este sentido, en la figura 2 se aprecia que de los 4 sectores de la cuadrícula, dos son internos (A y B) y dos externos que incluyen la pirca (C y D). La submuestra de carbones analizada procede de los sectores internos, principalmente del sector $A$, ya que presentaba mayor peso y cantidad de carbones. En aquellos casos en que no se contó con muestras para el sector A, se trabajó con el C, y solo cuando no se registraban carbones en estos dos, se trabajó con el sector D (ver Tabla 3)

Las muestras analizadas corresponden a carbones dispersos, recuperados por medio de la aplicación de la técnica de zaranda en seco, utilizando mallas de $3 \mathrm{~mm}$ de apertura a la totalidad del sedimento extraído por nivel (Neme 2007). Una segunda muestra de carbones procede de fogones o estructuras carbonosas. Se entiende por estructuras 


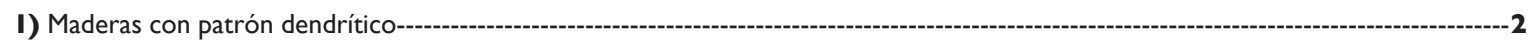

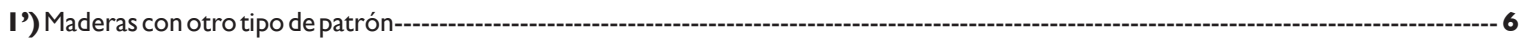

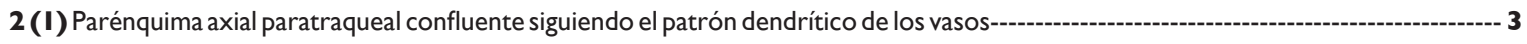

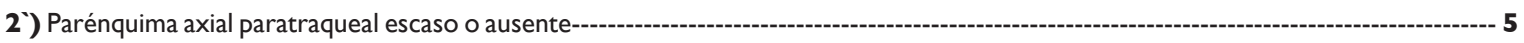

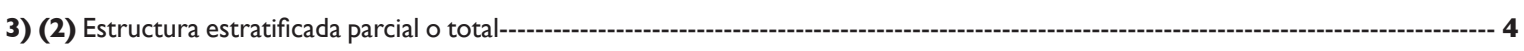

3') Sin estructura estratificada en parénquima y vasos, punteaduras alternas, vasos agrupados ausentes, elementos de vaso con

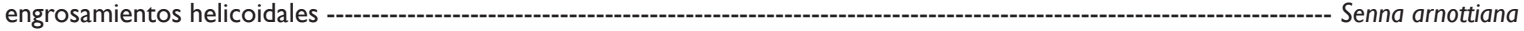

4)(3) Radios y/o elementos axiales irregularmente estratificados, punteaduras intervasculares alternas--------------------Anarthrophyllum

4') Estructura estratificada en vasos y parénquima, punteaduras intervasculares opuestas y escalariformes -

-

5) (2') Maderas con disposición ulmoide del leño temprano evidente, brazos del patrón dendrítico finos-------- Berberis raíz

5') Maderas en las que no se distingue disposición ulmoide en leño temprano, brazos del patrón dendrítico comúnmente gruesos -

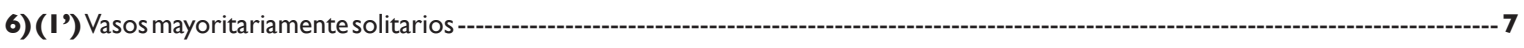

6') Vasos agrupados frecuentes o en series radiales--

7) (6) Elementos de vaso con placas de perforación escalariformes, punteaduras intervasculares escalariformes y opuestas ------------

-

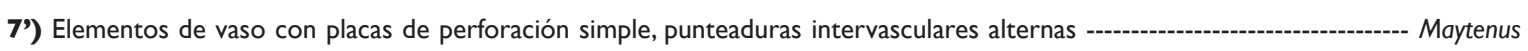

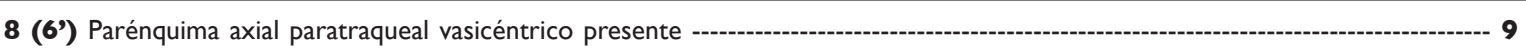

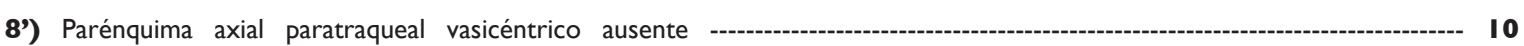

9) (8) Parénquima axial y/o elementos de vaso estratificados, elementos de vaso con engrosamientos reticulados presentes ------------

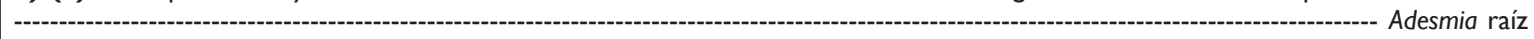

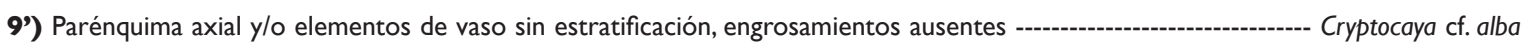

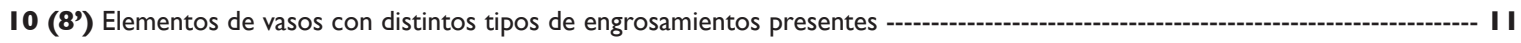

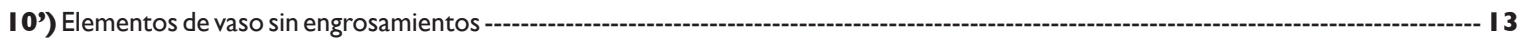

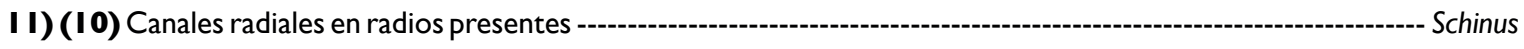

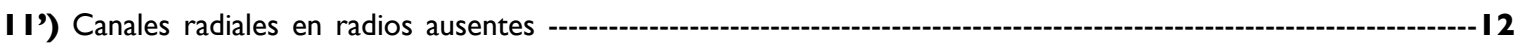

12) Tilosis común presente, radios mayormente multiseriados 3 (4)* 7 células ancho, en menor cantidad radios

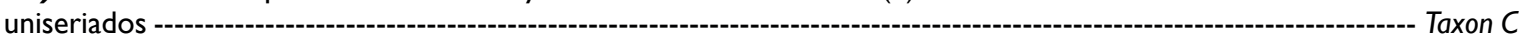

I2') Tilosis común ausente, radios I(2) 3 seriados-------------------------------------------Dasyphyllum cf. diacanthoides

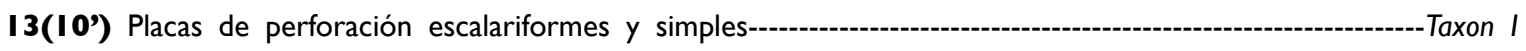

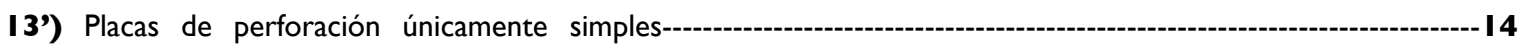

I4) (I3') Punteaduras intervasculares opuestas y también alternas con reborde circular o poligonal; radios I(3) 4 células ancho $(C L T)$, células procumbentes y cuadradas en la porción multiseriada y células cuadradas y erectas en

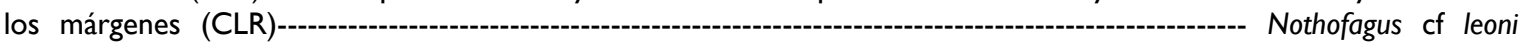

14') Punteaduras intervasculares alternas de reborde poligonal; radios mayormente I (3) 4 células ancho, formados por células en rectangulares erectas (CLT), radios con células erectas, cuadrangulares y procumbentes mezcladas (CLR)

Grindelia

Tabla 2: Clave dicotómica utilizada en el análisis antracológico de El Indígeno. Referencia * entre paréntesis se expresa la moda mientras que los valores de los extremos refieren a los valores máximo y mínimo de células contadas

Table 2: Dichotomous key used in the anthracological analysis of El Indigeno. Reference * mode in parenthesis expressed while those extreme values refer to the maximum and minimum number of cells counted. 
carbonosas a un rasgo observado durante la excavación del sitio que consiste en concentraciones de carbones, asociadas a sedimentos termoalterados, las cuales fueron mapeadas y recuperadas in situ, además de ser embaladas por separado del resto de los carbones de nivel y sector que las contenían. Dichos rasgos, no implican necesariamente estructuras definidas espacialmente como pircas o cubetas de origen claramente antrópico. Durante la excavación de la cuadrícula B2 se registraron 16 estructuras carbonosas de distintas dimensiones y características, las cuales fueron registradas como fogones, fogoncitos $y$, en algunas casos, con un signo de interrogación. En el sector $\mathrm{A}$ se registraron seis de estos rasgos arqueológicos, de los que se analizaron únicamente aquellos que figuraban como "fogones". En un solo caso coincidía la ubicación tridimensional de dos rasgos de niveles sucesivos (niveles 6 y 7 , registro tridimensional 93 y 108 respectivamente), por lo cual interpretamos que se trataba de un mismo evento de combustión, el cual fue analizado como una unidad y designado como Fogón A. El siguiente fogón analizado se registró en el nivel 9 (registro tridimensional I33= Fogón B).

Previo al análisis antracológico se discriminaron los carbones en tres tamaños distintos: a- entre 3 y $5 \mathrm{~mm}$, b- entre 5 y $10 \mathrm{~mm}$, c- > a $10 \mathrm{~mm}$, con el fin de tomar sucesivamente un carbón de cada clase diamétrica para no sesgar la muestra a favor de uno u otro tamaño (Thièbault 1989). Para cada una de las 10 submuestras de carbones dispersos, así como para los 2 fogones seleccionados, la cantidad de carbones analizados fue definida por medio de la construcción de una "curva de riqueza específica" (Badal 1992; Chabal 1988, 1990; Marconetto 2005, Piqué i Huerta 1999). Todos los carbones fueron fracturados a mano para el reconocimiento de los rasgos diagnósticos que se realizó con microscopio Leica MDL con luz incidente.

Los parámetros estadísticos utilizados en el presente trabajo fueron: cantidad absoluta y frecuencia relativa \% de taxa (basada en la variable anterior), tanto por nivel y/o estructura carbonosa, como por ocupación y en la secuencia completa del sitio (Smart y Hoffman 1988). También se calculó la ubicuidad de cada taxon (porcentaje de las muestras en que cada taxon estuvo presente). Esta variable, en el caso de los carbones dispersos, nos muestra cuán sostenido fue el uso de un taxon a lo largo del período de ocupación y del sitio en general. Para evaluar si las diferencias observadas en las distintas ocupaciones son o no significativas se ha optado por realizar cálculos de chi-cuadrado $\left(X^{2}\right)$, en base a la cantidad absoluta (Adriano-Morán y Tapia 2008). Se considera que si $p<0,05$, las diferencias son significativas. La aplicación de $\mathrm{X}^{2}$ tiene a nuestro entender una ventaja y una desventaja. La primera es que nos permite evaluar si las variaciones en las frecuencias absolutas por taxa son o no significativas en relación al total de los carbones analizados por cada una de las ocupaciones que se desea comparar, mientras que la desventaja es que no nos permite confrontar aquellos taxa que se presentan en una sola de las ocupaciones. Para la confección del perfil antracológico del sitio se utilizó el software C2 versión I.7.2 (Juggins 2007).

\section{RESULTADOS}

Se contabilizó un total de 3.248 carbones en los sectores seleccionados para su estudio (Tabla 3). Se analizó una submuestra de 277 , lo que representa el $8,49 \%$ del total, de éstos se identificó el $90,25 \%$ (249 carbones). Considerando tanto los carbones dispersos, como los contenidos en los fogones $A$ y $B$, se reconocieron representantes de 14 taxa vegetales (Tabla 3 ) que se distinguen en términos de frecuencia relativa (\%) (Figura 3a): Adesmia (30,33\%) -tallo $(6,86 \%)$ y raíz/tallo (23,55\%)-, Escallonia (22,83\%), Maytenus (6,52\%), Anartrophyllum (6,16\%), Taxon C' (5,43\%), Schinus (4,35\%), Nothofagus of. leoni, Berberis raíz (3,26\%), Ochetophila (2,90\%), Senna (2,54\%) Cryptocarya cf. alba (0,72\%), Dasyphyllum cf. diacanthoides, Grindelia y Taxon I2 (0,36\%). En cuanto al porcentaje de ubicuidad (Figura 3b), los únicos taxa con el $100 \%$ de ubicuidad son Adesmia (raíz/tallo) y Escallonia, seguidos por el Taxon C (77,78\%), Adesmia tallo,Anartrophyllum, Berberis raíz y Maytenus (66,67\%). Valores menores al $50 \%$ presentaron Nothofagus of. leoni (44,44\%), Schinus, Senna y Ochetophila $(33,33 \%)$ y Cryptocarya cf. alba, Dasyphyllum of. diacanthoides, Grindelia y Taxon I (I I, I I\%).

El perfil antracológico de El Indígeno (Figura 4) nos permite apreciar los cambios en las frecuencias porcentuales de los taxa, a lo largo de la secuencia del sitio. Se evidencia que el uso de leña se centró principalmente en dos géneros: Adesmia 


\begin{tabular}{|c|c|c|c|c|c|c|c|c|c|c|c|c|}
\hline \multirow[b]{2}{*}{$\begin{array}{l}\text { Niveles } \\
\text { Fogones (Fg.) }\end{array}$} & \multicolumn{3}{|c|}{$2^{\circ}$ Ocupación } & \multicolumn{8}{|c|}{ I’Ocupación } & \multirow[b]{2}{*}{ Total } \\
\hline & 2 & 3 & 4 & 5 & 6 & $\begin{array}{l}6 / 7 \\
F g . A\end{array}$ & 7 & 8 & 9 & $\begin{array}{c}9 \\
\text { Fg. B }\end{array}$ & 10 & \\
\hline Sector & $\mathbf{A}$ & $\mathbf{A}$ & C & $\mathbf{A}$ & C & $\mathbf{A}$ & D & $\mathbf{A}$ & $\mathbf{A}$ & $\mathbf{A}$ & $\mathbf{A}$ & \\
\hline $\mathrm{N}^{\circ}$ total de restos recuperados & 190 & 198 & 89 & 406 & 382 & 599 & 204 & 381 & 344 & 227 & 228 & 3248 \\
\hline Peso total de restos recuperados $(\mathrm{g})$ & 10,3 & 6,3 & 3,9 & 15,5 & 17,7 & 37,7 & 11,2 & 27,3 & 25,7 & 27,9 & 16,4 & 199,9 \\
\hline Adesmia Raíz/tallo & 7 & 5 & 2 & 5 & 2 & - & 6 & II & 10 & 9 & 8 & 65 \\
\hline Adesmia tallo & - & $\mathrm{I}$ & $\mathrm{I}$ & - & - & I & - & 2 & 5 & I & 8 & 19 \\
\hline Anartrophyllum & - & 1 & 3 & 4 & - & 3 & 4 & 2 & - & - & - & 17 \\
\hline Berberis Raíz & - & - & 3 & I & 1 & 2 & 2 & - & - & - & - & 9 \\
\hline Cryptocarya cf. alba & - & - & - & 2 & - & - & - & - & - & - & - & 2 \\
\hline Dasyphyllum cf. diacanthoides & - & - & - & - & 1 & - & - & - & - & - & - & I \\
\hline Escallonia & 6 & 9 & 8 & 12 & 6 & 4 & 3 & I & I & II & 2 & 63 \\
\hline Grindelia & - & - & - & - & - & - & - & - & I & - & - & I \\
\hline Maytenus & 7 & - & - & I & - & 7 & 2 & - & - & - & I & 18 \\
\hline Nothofagus cf. leoni & - & - & - & - & 1 & 7 & 3 & - & - & - & - & II \\
\hline Ochetophila & - & - & - & - & 4 & 3 & - & - & I & - & - & 8 \\
\hline Schinus & - & - & - & - & - & II & - & - & - & - & I & 12 \\
\hline Senna & - & - & 4 & I & 2 & - & - & - & - & - & - & 7 \\
\hline Taxon C & - & 3 & $\mathrm{I}$ & - & 2 & 5 & - & 3 & - & - & $\mathrm{I}$ & 15 \\
\hline Taxon I & - & - & - & - & - & - & - & - & - & - & I & I \\
\hline Indeterminables & I & 5 & 2 & 3 & 2 & 6 & I & 2 & 3 & - & 2 & 27 \\
\hline Total analizado & 21 & 24 & 24 & 30 & 21 & 49 & 21 & 21 & 21 & 21 & 24 & 276 \\
\hline Peso de restos analizados (g) & 3,3 & 2,1 & 2,5 & 3 & 4,3 & 6,9 & 2,9 & 5,2 & 3,3 & $\mathrm{II}, \mathrm{I}$ & 4 & \\
\hline $\mathrm{N}^{\circ}$ de restos por ocupación & \multicolumn{3}{|c|}{69} & \multicolumn{8}{|c|}{187} & \\
\hline Peso de restos analizados por ocupación & \multicolumn{3}{|c|}{7,9} & \multicolumn{8}{|c|}{40,7} & \\
\hline
\end{tabular}

Tabla 3: Cantidad absoluta de carbones recuperados y de carbones analizados en El Indígeno. Valores por nivel, ocupación y por especie. Table 3: Absolute quantity of recovered and analyzed charcoal in El Indígeno. Values per level, occupation and species

y Escallonia. En relación a éstos se observa que en los niveles más profundos (niveles 8,9 y I0), y considerando únicamente los carbones dispersos, el uso de maderas para leña se concentró en Adesmia; mientras que, a partir del nivel 7, donde la frecuencia de Adesmia disminuye, se incrementa la de Escallonia, mientras que al disminuye la frecuencia de ambas, aumenta la frecuencia de otros taxa como Anartrophyllum, Berberis raíz, Senna, Maytenus, Ochetophila y Nothofagus.

En el registro antracológico de la primera ocupación se contabilizaron 1945 carbones dispersos, de los cuales se analizó un total de 138 carbones identificándose el 90,58\% (I25 carbones). Se reconocieron 14 taxa, los cuales se distinguen en términos de frecuencias (\%) (Figura 5a): Adesmia $(41,3 \%)$-raíz/tallo $(30,43 \%)$ y tallo $(10,87 \%)$-, Escallonia (18,12\%), Anartrophyllum (7,25\%), Taxon C $(4,35 \%)$, Berberis raízy Ochetophila (3,62\%), Maytenus y Nothofagus of. leoni (2,90\%), Senna (2, I7\%), Cryptocarya cf. alba (I,45\%) y Dasyphyllum cf. diacanthoides, Grindelia, Schinus, Taxon I(0,72\%). Para el conjunto antracológico de la segunda ocupación se contabilizaron 477 carbones dispersos, de los cuales se analizaron 69 , identificándose el $88,41 \%$ (6I carbones). Se reconoció la presencia de 7 taxa, los cuales se distinguen en términos de frecuencias (\%) (Figura 5a): Escallonia (33,33\%), Adesmia (23,10\%) -raíz/tallo $(20,29 \%)$ y tallo (2,90\%)-, Maytenus 


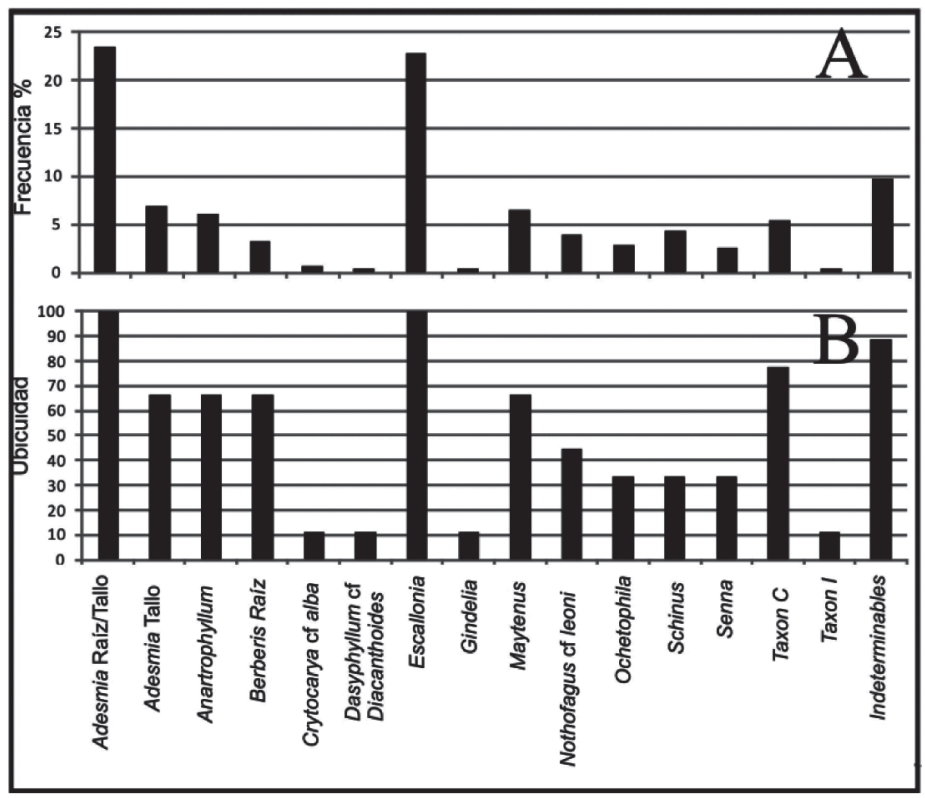

Figura 3: A) Frecuencias relativas (\%) de cada taxon en la secuencia arqueológica general de El Indígeno, basadas en el conteo de fragmentos. B) Porcentajes de ubicuidad de cada taxon en la secuencia arqueológica general de El Indígeno.

Figure 3: A) Relative frequencies (\%) of each taxon in the general archaeological sequence of El Indigeno, on the base of fragment counts. B) Percentage of ubiquity for each taxon of the general archaeological sequence of El Indigeno.

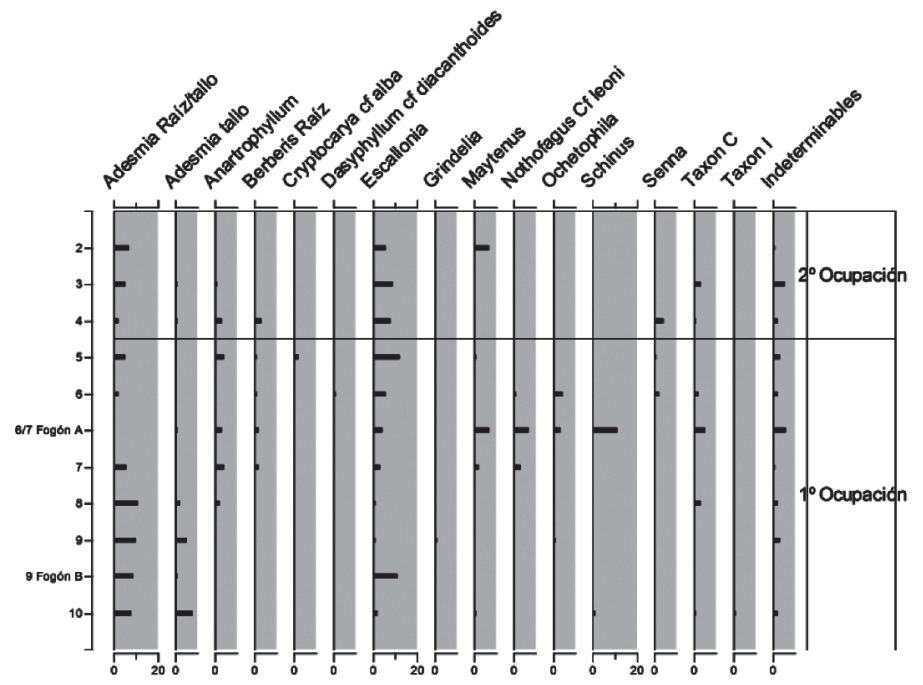

Figura 4: Perfil antracológico de El Indígeno realizado sobre la base la cantidad absoluta de cada taxa.

Figure 4: El Indigeno anthracological profile undertaken on the basis of the absolute quantity of each taxon 
(10,14\%), Anartrophyllum, Senna y Taxon C (5,80\%), Berberis raízy (4,35\%). En cuanto a la ubicuidad los únicos taxa con el $100 \%$ en ambas ocupaciones son Adesmia (tallo/raíz) y Escallonia (Figura 5b). Los taxa secundarios en términos de ubicuidad en la primera ocupación son Anartrophyllum, Berberis raíz y Taxon C (50\%), seguidos de Nothofagus cf. leoni y Senna (33,33\%),y finalmente Cryptocarya cf.alba, Dasyphyllum cf. diacanthoides, Grindelia, Ochetophila,Schinus y Taxon I(I6,66\%). Mientras que en la segunda ocupación los taxa secundarios son Anartrophyllum y Taxon C (66,66\%), en menor proporción Berberis raíz, Maytenus, y Senna (33,33\%) (Figura 5b).

La aplicación del test de $\mathrm{X}^{2}$ a los conjuntos antracológicos de El Indígeno fue realizada a un total de 9 muestras (Adesmia, Adesmia tallo/raíz, Adesmia tallo, Berberis, Anartrophyllum, Escallonia, Maytenus, Senna y Taxon C), entre las cuales están representados 6 géneros distintos (Adesmia, Berberis, Anartrophyllum, Escallonia, Maytenus, Senna y Taxon C). Los resultados indican que las variaciones en las frecuencias de Adesmia $\left(X^{2}=5,72 p=0,016\right)$, Escallonia $\left(X^{2}=7,85 p=0,005\right)$ y Maytenus $\left(X^{2}=5,73, p=0,023\right)$ son estadísticamente significativas. Para Escallonia las diferencias fueron altamente significativas.

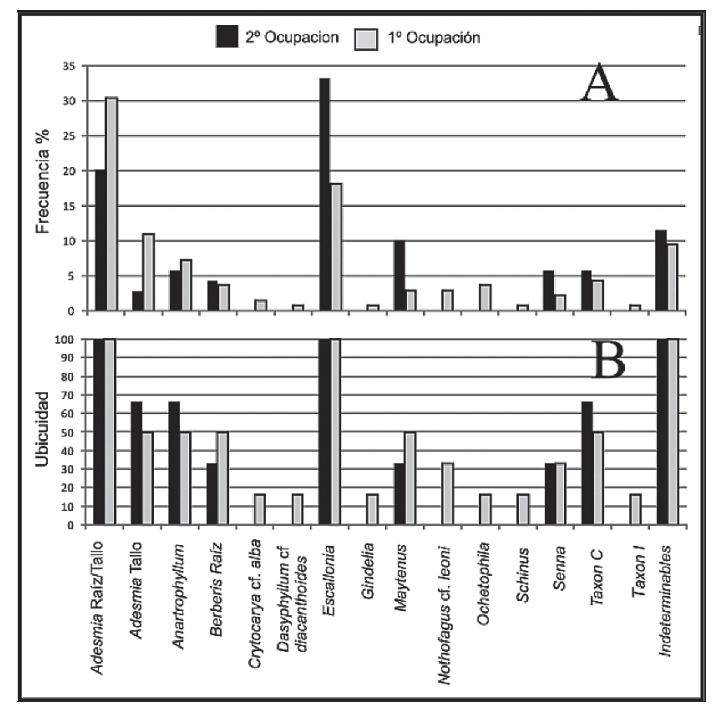

Figura 5: A) Gráfico comparando las frecuencias porcentuales en ambas ocupaciones, en base al conteo de fragmentos; B) Gráfico comparando los porcentajes ubicuidad de cada taxon entre las dos ocupaciones.

Figure 5: A) Graphic comparing the percentage frequencies in both occupations, based on fragment counts; B) Graphic comparing percentage ubiquity of each taxon between both occupations.

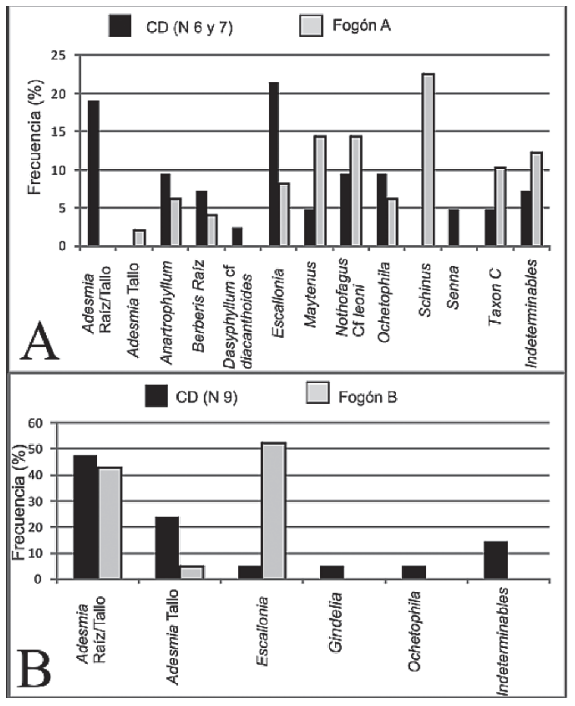

Figura 6: Comparación entre las frecuencias observadas en los dos Fogones analizados y sus respectivos niveles. A) Fogón A comparado con la suma de los carbones dispersos (CD) de los niveles 6 y 7. B) Fogón B comparado con los carbones dispersos (CD) del nivel 9.

Figure 6: Comparison between the observed frequencies in the two hearth analyzed and their respective levels. A) Hearth A compared to the sum of the scattered charcoal (CD) levels 6 and 7. B) Hearth $B$ compared to the scattered charcoal (CD) level 9.

Es interesante observar que Adesmia presentó diferencias significativas únicamente cuando se la comparó a nivel de género, y no a nivel de estructuras anatómicas (tallo/raíz y tallo).

De la comparación entre los fogones y los carbones dispersos se pueden apreciar algunas diferencias y similitudes, tanto en términos de presencia/ausencia de taxa como en sus frecuencias (Figura $6 a$ y b). En el Fogón A (niveles 6 y 7) se contabilizó un total de 599 carbones, se analizó el $8,18 \%$ (49 carbones), de éstos se identificó el $87,76 \%$ (Tabla 3). Se reconocieron 9 taxa, los cuales se distinguen en términos de frecuencia relativa (\%) (Figura 6a): Schinus (22,45\%), Maytenus y Nothofagus cf. leoni (14,29\%), Taxon C (I0,20\%), Escallonia (8, I6\%), Anartrophyllum y Ochetophila $(6,12 \%)$, Berberis raíz $(4,08 \%)$ y Adesmia tallo (2,04\%). Respecto del Fogón B (nivel 9) se contabilizó un total de 227 carbones, se analizó el 9,25\% (2I carbones), identificándose el $100 \%$. Se reconoció la presencia de 2 géneros (Figura 6-B), que se distinguen en términos de frecuencia relativa (\%): Adesmia (47,62\%) -raíz/tallo (42,86\%) y 
tallo (4,76\%)- y Escallonia (52,38\%). En términos de diversidad se registra una mayor diversidad en los carbones dispersos de los niveles que contenían a los fogones que en estos últimos en sí mismos, en este sentido en el Fogón A son 9 los taxa identificados mientras que entre los niveles 6 y 7 la diversidad es de 10 taxa (Figura 6a); en cuanto al Fogón B son 2 los taxa identificados mientras que entre los carbones dispersos del nivel 9 se reconocieron 4 taxa (Figura 6b).

\section{DISCUSIÓNY CONCLUSIONES}

La ubicación de El Indígeno a 3300 msnm, las dimensiones del sitio y la diversidad de materiales arqueológicos recuperados le confieren características particulares. Si bien existen otros sitios arqueológicos de altura en la región, por ejemplo Los Peuquenes, y una serie de sitios con estructuras pircadas en la Laguna del Diamante (Lagiglia 1997, Durán et al. 2006, Neme 2007, Neme y Gil 2013), ninguno tiene la concentración de estructuras habitacionales de El Indígeno. Su registro arqueológico se caracteriza por la diversidad de materiales (líticos, cerámicos, arqueobotánicos, arqueofaunísticos, instrumentos de molienda, entre otros). El registro antracológico, en particular, presenta una importante diversidad taxonómica $(\mathrm{n}=$ I4 taxa). A pesar de dicha diversidad, más del $50 \%$ del registro antracológico general está representado por dos géneros: Adesmia y Escallonia. Ambos se encuentran en todos los niveles analizados. Respecto a Adesmia, se encuentra disponible en la zona, tal como se apreció durante las campañas de excavación por lo que habría constituido un recurso local.

Las Adesmias, en todas partes de la cordillera mendocina, proporcionan la leña que los arrieros y montañeses usan como combustible, de allí que la llaman "la leña” (Ruiz Leal 1972, Andreoni 2010). Estudios de densidad realizados por nosotros permiten caracterizarla como una madera semidura, además de proporcionar tallos y raíces de diámetro considerable (Andreoni 20I4), el género Adesmia está bien representado en otros sitios de la región (Andreoni 20I4, Andreoni y Capparelli 2012). Respecto de Escallonia, distintas especies de este género crecen en los valles de Chile, entre éstas Escallonia alpina, E. illinita, E. revoluta,E. pulverulenta, E. virgata, E. rubra,y E. myrtoidea (Solari 1993, Muñoz-Schick et al. 2000). Su distribución puede establecerse entre las cotas de 1000 a 2000 msnm abarcando el Matorral esclerófilos y Matorral subandino (aproximadamente 40 a $50 \mathrm{~km}$ del sitio) (Solari 1993; Rancusi et al. 1987; MuñozSchick et al. 2000). Mientras que en Mendoza, se registra E.myrtoidea a orillas del arroyo La Remonta y en Malargüe (ambos a unos $100 \mathrm{~km}$ del sitio) (Ruiz Leal 1972, Darwinion 2014), además E. illita var. carmenilitana en una amplia franja altitudinal de 100 a 3000 msnm (Darwinion 20l4), aunque no tenemos precisión de que pueda encontrarse en las proximidades del sitio. Considerando la distribución de este género y las especies de mayor cercanía, es posible que la madera de Escallonia, utilizada para leña en El Indígeno, proceda de Chile pero no podemos descartar totalmente una procedencia del lado argentino. De todos los sitios estudiados en la región, por el momento es en El Indígeno el único donde hemos identificado este género (Andreoni 20I4). Respecto de su calidad como combustible, los estudios de densidad realizados por Ciampagna (20I5) en especies de la Patagonia argentina indican que se trata de una madera blanda y liviana, además sus frutos son comestibles (Solari 1993).

Entre los restantes taxa identificados debemos diferenciar aquellos que son de ambiente Patagónico, que crecen en cotas altitudinales inferiores al sitio $y$ en ambas vertientes de la cordillera (i.e. Maytenus, Anartrophyllum, Schinus, Senna, Ochetophila, Berberis y Grindelia), de aquellos que aparecen en ambientes alejados del sitio o cuya distribución es más acotada (i.e. Nothofagus cf. leoni, Cryptocarya cf. alba, Dasyphyllum cf. diacanthoides yprobablemente Taxon C y Taxon I). En el primer grupo algunos taxa (i.e. Anartrophyllum, Schinus, Senna, Ochetophila, Berberis) poseen buenas propiedades como combustible, son maderas semi-duras y están representados también en otros registros antracológicos de la región (Andreoni 2014; Andreoni y Capparelli 20 I2; Llano y Andreoni 20I2). En cuanto a Dasyphyllum, Cryptocarya y Nothofagus pueden haber sido trasladadas desde el Matorral esclerófilo o desde Matorral subandino. El género Dasyphyllum cuenta con dos representantes en Chile, $D$. excelsum y $D$. diacanthoide, el primero de éstos con una distribución restringida a la Cordillera de la Costa, en las provincias de Santiago y Valparaíso 
(Cabrera 1959), mientras que D. diacantoide presenta una distribución más amplia, desde Curicó hasta Chiloé y es un árbol de gran porte que habita entre los 200 y 800 msnm (Cabrera 1959). Respecto de Nothofagusleoni, árbol que crece en la Cordillera de la Costa y en la Cordillera de Los Andes, entre $34^{\circ} \mathrm{S}$ y $36^{\circ} \mathrm{S}$, a $70 \mathrm{~km}$ aproximadamente del sitio, es una especie que se da asociada a $N$. olicua y $N$. glauca (Rancusi et al. 1987). Por último, Cryptocaryaalba es un árbol cuya distribución se extiende desde Coquimbo $\left(30^{\circ} \mathrm{S}\right)$ a Cautín $\left(39^{\circ} \mathrm{S}\right)$, principalmente en la zona central de esta distribución $(70 \mathrm{~km}$ aproximadamente del sitio), y que según Rancusi et al. (1987) no excede los $800 \mathrm{msnm}$. Sin embargo, Muñoz-Schick et al. (2000) consideran que este taxon es indicador del límite altitudinal del estrato arbóreo de los valles que forman la cuenca del río Maipo, extendiéndose su altitud hasta los 1700 msnm, por lo que se podría encontrar a menor distancia del sitio (aproximadamente $50 \mathrm{~km}$ ).

Volviendo al análisis antracológico de la primera ocupación del sitio, la cual se corresponde con el estilo cerámico Llolleo, del Periodo Alfarero Temprano de Chile Central (I470 años ${ }^{14} \mathrm{C}$ AP) (Neme 2007), ésta presentó una diversidad de 14 taxa. Sin embargo, hubo un énfasis en la utilización de Adesmia (casi el 50\%) y de Escallonia, en segundo lugar, a las cuales se suman plantas leñosas de la zona que crecen a niveles altitudinales menores, así como otras procedentes claramente de la vertiente occidental de la cordillera (i.e. Nothofagus, Cryptocarya y Dasyphyllum), las cuales están ausentes en la segunda ocupación del sitio (ver más adelante). Lagiglia (1997) interpreta que El Indígeno formaría parte de un circuito de movilidad de grupos cazadores recolectores cordilleranos, con circuitos de trashumancia, estos grupos se asentarían en el piedemonte y la llanura oriental en invierno (1600 msnm) y durante el verano se desplazarían hacia los valles interandinos (entre 2000 y 4000 msnm) y bajarían ocasionalmente hacia la vertiente occidental (Chile) para intercambiar productos en los valles del Maipo y/o Cachapoal/Tinguiririca (Lagiglia 1997). Por otro lado, Sanhueza et al. (2004) considera que El Indígeno podría ser parte de un circuito de movilidad de los grupos Llolleo que accederían al sitio “... desde la cuenca y precordillera de Santiago por el valle del Maipo, o desde la región de Rancagua subiendo por el río Cachapoal, Las Leñas u otro..."
(Sanhueza et al. 2004:124). Siguiendo esta misma línea de pensamiento Cornejo y Sanhueza (2003, $20 \mathrm{Il}$ a y b) analizan el registro arqueológico del Valle del Maipo, Chile Central, observando a partir del registro lítico, cerámico y el patrón de asentamiento que en esta región de Chile se dio una coexistencia de grupos con una economía extractiva (cazadores recolectores) y otros con economía productiva (horticultores). Para dichos autores El Indígeno representa una ocupación de grupos cazadores recolectores, cuyo tipo de estructuras pircadas se corresponde al definido como "patrón constructivo Perdidas"3 (Cornejo y Sanhueza 201 I a y b). Este mismo patrón de asentamiento se reconoce en el sector de Laguna de El Diamante, aquí también asociado a cerámica de Chile. Durán et al. (2006) define dos ocupaciones en este último sector; la primera asociada a material Llolleo, que cronológicamente abarca desde los 2100 a 1100 años AP y una segunda ocupación que abarca desde los 1100 a 500 años AP donde se registra cerámica correspondiente al Complejo Aconcagua. Finalmente considera que los sitios de Laguna de El Diamante se corresponderían a grupos de la vertiente occidental de de la Cordillera de Los Andes (Durán et al. 2006).

Volviendo al sitio El Indígeno, la procedencia de la vertiente occidental de la cordillera de al menos cuatro de los taxa identificados en el registro antracológico para este periodo, soporta las hipótesis de conexión entre una y otra vertiente cordillerana con un flujo importante de maderas que está siendo colectada en la flanco occidental cordillera. Incluso, este hecho nos permite hacer un análisis más profundo a lo largo del tiempo. Por ejemplo, cuando miramos al interior de esta primera ocupación se observan algunas diferencias importantes en el registro de uso de leña de las primeras etapas con respecto a las últimas. Llamativamente, el uso relativo de Adesmia en las primeras etapas (niveles 8 a 10) es siempre cercano al $50 \%$. Sin embargo, en las últimas (niveles 5 a 7) las frecuencias de Adesmia no sobrepasan el $20 \%$, a la vez que hay un paulatino incremento en las frecuencias de taxa que estuvieron presentes en los niveles inferiores con valores menores (i.e. Taxon C, Maytenus,), se suman al registro los taxa de niveles altitudinales menores (i.e. Berberis, Anartrophyllum, Senna y Schinus), así como las maderas procedentes de la vertiente occidental de la cordillera (i.e. Nothofagus, Cryptocarya y Dasyphyllum). Una situación 
similar se observa en los fogones $A$ y $B$. En este sentido, en el Fogón $B$ (el más antiguo) Adesmia y Escallonia representan los únicos taxa identificados; mientras que en el Fogón A (el más reciente de la primera ocupación), la frecuencia de Adesmia es muy baja y el registro antracológico más diverso $(n=9)$, donde está presente incluso Nothofagus. Si bien estas diferencias podrían responder a la realización de actividades distintas entre un periodo y otro, dentro del seno de un mismo tipo de sociedad, la gestión de leña entre estos dos periodos parecería haber cambiado significativamente. No obstante, considerando las dimensiones del sitio y que solo contamos con la secuencia antracológica de un recinto, que posee una forma distinta al resto (la mayoría son circulares o semicirculares y el recinto 96 es rectangular), es posible que lo que haya cambiado hayan sido las actividades específicas que se llevaron a cabo en este recinto particular, o los grupos sociales que tuvieron acceso a él. Otra posibilidad sería que un uso más intenso de Adesmia al comienzo de la ocupación de El Indígeno haya llevado a una disminución en la disponibilidad de leña de este taxon para la segunda mitad de la primera ocupación y esto haya provocado las diferencias en las estrategias de gestión de leña. Sin embargo, la leña de base (en este caso Adesmia) podría haber sido reemplazada por otras varias leñas locales, tal como ocurre en otros sitios del sur mendocino (Andreoni 2014, Andreoni y Capparelli 20I2). En El Indígeno, no sólo aumenta la diversidad e intensidad de uso de otras leñas locales, sino que aparecen maderas de la vertiente occidental de la cordillera.

De la comparación entre los carbones dispersos en el sedimento de El Indígeno y los concentrados en estructuras carbonosas se aprecian algunas otras diferencias, además de las mencionadas anteriormente. La primera y más evidente es la menor diversidad taxonómica de los fogones ( $n=9$ géneros) con respecto a la de los carbones dispersos en el sedimento ( $n=14$ géneros). Entre los taxa identificados en el Fogón $A$ se observa que algunas especies tienen mayor frecuencia dentro de las estructuras carbonosas que entre los carbones dispersos (i.e. Schinus y Maytenus). Otros aspectos contrastantes entre estos dos tipos de registro es la baja frecuencia de Adesmia en el Fogón A y la presencia en éste, en cantidades importantes, de carbones de Nothofagus cf. leoni. El Fogón B presenta una diversidad de 2 géneros (Adesmia y Escallonia) y las especies registradas en el Fogón $B$ coinciden con las mejor representadas en el sitio en general. Habitualmente se considera que los carbones dispersos nos proveen información que resulta de un promedio de todas las actividades ligadas con el fuego, realizadas en un sitio en un momento dado, sin embargo nos brindan escasa información acerca de las características de cada una de las actividades desarrolladas en particular (Piqué i Huerta 1999). Por el contrario, los carbones procedentes de concentraciones o de estructuras de combustión son rasgos que nos brindan información más específica del uso de leña, ya que responden a actividades acotadas, por lo que se espera que las muestras procedentes de fogones sean menos diversas, e incluso monotípicas (Chabal 1990; Zapata y Figueiral 2003). En El Indígeno sí se evidenció menor diversidad en los fogones pero no hay fogones monotípicos.

La segunda ocupación del sitio se habría dado a partir de los 980 años ${ }^{14} \mathrm{C}$ AP, la misma ha sido vinculada al estilo cerámico Aconcagua del Periodo Intermedio Tardío de Chile Central (Lagiglia et al. 1994, Lagiglia 1997, Neme 2007). En términos de la secuencia antracológica, durante esta ocupación se aprecia una continuidad en la utilización de los recursos combustibles, dado que Adesmia y Escallonia son los géneros mejor representados, aunque en este componente es Escallonia, y no Adesmia, el taxon con valores más elevados en términos de frecuencia relativa. Estas variaciones en las frecuencias antracológicas fueron estadísticamente significativas para ambos taxa, así como para Maytenus. A diferencia de la primera ocupación, aquí se observa una disminución en la diversidad. Uno de los aspectos más llamativos de esta disminución en la diversidad es que entre los taxa ausentes se encuentran aquellos cuya procedencia podíamos claramente asignar a la vertiente occidental de la Cordillera de Los Andes (i.e. Dasyphyllum, Cryptocarya y Nothofagus), aunque se observa un incremento en Escallonia, taxon que, como dijimos anteriormente, también pudo ser traído desde los valles de Chile.

Como se mencionó en la metodología de este trabajo, una de las expectativas que teníamos previo al análisis antracológico era encontrar, dentro del registro, distintos tipos de yaretas (i.e. Azorella spp, Mulinumspp, Oxalis sp., entre otras). Sin embargo, no hemos identificado ninguno de estos taxa. Esta 
ausencia posiblemente no signifique una ausencia de su uso, sino que pueden haber sido utilizados pero no preservados en el registro. Las experimentaciones realizadas por nosotros evidenciaron que tanto Azorella nucamentosa como Mulinum valentinii poseen baja densidad y combustionan con gran facilidad por la presencia de resinas. Tras la carbonización estos ejemplares se encontraban cubiertos de ceniza y fuertemente deteriorados, por lo cual posiblemente su exposición a fuegos prolongados puede disminuir su presencia en el registro antracológico (Andreoni 20I0).

A modo de conclusión, consideramos que los resultados obtenidos del análisis antracológico de El Indígeno aportan nuevos elementos que permiten enriquecer el conocimiento que hasta el presente se tenía de este sitio y de sus implicancias en la arqueología del COA y de Chile Central. Además hemos comprobado que la escasa oferta ambiental de recursos combustibles en la Alta Cordillera llevó a las sociedades que ocuparon el sitio a gestionar los recursos combustibles por medio de la aplicación de distintas estrategias de abastecimiento. En las primeras ocupaciones la leña colectada fue mayormente local (i.e. Adesmia), no obstante ésta siempre fue acompañada por maderas procedentes posiblemente de los Matorral Esclerófilos Chilenos (i.e. Escallonia y Taxon C). Dada las dimensiones del sitio y las condiciones ambientales en las que se encuentra creemos que la demanda de combustibles debió ser elevada. Por lo cual, los ritmos de regeneración de las plantas de Adesmia debieron ser superados por los ritmos de extracción o producción de madera muerta, lo cual pudo haber obligado a las poblaciones humanas a desarrollar nuevas estrategias en la gestión de los recursos combustibles. En este sentido, a medida que se sucedieron las ocupaciones del sitio la leña utilizada debió ser trasladada desde distintos ambientes, ya sea desde pisos ecológico inferiores en ambas vertientes de la cordillera, o bien desde ambientes ubicados a mayor distancia. Los cambios observados en la segunda ocupación pueden responder a distintos factores, por un lado a la disminución en la oferta ambiental de taxa locales, y por otro, si consideramos que los grupos de cazadores recolectores durante el Periodo Intermedio Tardío se encontraban restringidos a los valles intermontanos, es plausible explicar la ausencia de especies arbóreas por cambios en el acceso a las partes bajas de los valles, ocupadas en ese momento por grupos agricultores del denominado complejo Aconcagua. Finalmente los resultados expuestos, si bien no pueden ser utilizados para realizar una asignación cultural del grupo que ocupó El Indígeno, sí están señalando un fuerte énfasis en la obtención de recursos combustibles de los valles de Chile Central.

Agradecimientos: A Aylen Capparelli por el acompañamiento en el proceso de trabajo y por la revisión del manuscrito. A Adolfo Gil, Gustavo Neme por las sugerencias realizadas durante el trabajo. AI CONICET (PIP 0459, titular A. Capparelli) y a la Facultad de Ciencias Naturales y Museo de La Plata (Proyecto N592, titular A. Capparelli), por el soporte financiero.A los evaluadores por enriquecer de forma crítica y desinteresada el presente manuscrito.

\section{NOTAS}

I Respecto del Taxon C es importante resaltar que el mismo presentó características anatómicas afines a Peumus boldo, especie que crece en los Bosques Esclerófilos, pero las mismas no resultaron definitorias para su asignación.

2 En cuanto al Taxon I es posible que este taxon se corresponda a alguna especie de Nothofagus spp., sin embargo el mal estado de preservación del carbón no permitió la observación de todos los rasgos diagnósticos de este género.

3 Caracterizado por el registro de entre 3 y 7 estructuras pircadas que delimitan los bordes exteriores de una oquedad circular levemente excavada en el suelo (Cornejo y Sanhueza 20II a)

\section{BIBLIOGRAFÍA}

Adriano-Moran, C.C. y E. Mc Clung de Tapia. 2008. "Trees and shrubs: the use of wood in prehispanic Teotihuacan". Journal of Archaeological Science 35:2927-2936.

Andreoni, D.F. 2010. “La importancia de la colección de referencia para los análisis antracológicos, en el sur de Mendoza". Actas ICES 5:30-39.

Andreoni, D.F. 2014. Plantas leñosas y estrategias humanas en el sur de Mendoza: una aproximación arqueobotánica Tesis Doctoral Inédita. Facultad de Ciencias Naturales y Museo, Universidad Nacional de La Plata.

Andreoni, D.F. 2015. "Explotación de recursos combustibles en el monte Mendocino: el caso del sitio arqueológico Agua de los Caballos - I (departamento de San Rafael)". Intersecciones en Antropología 16: 253-269

Andreoni, D.F. y A. Capparelli. 2012. "El ser humano y la leña en la cordillera de Mendoza (Argentina), a lo largo del Holoceno: sitio arqueológico Arroyo Malo 3". Magallania 40(I): 199-224. 
Andreoni, D., A. Gil y A. Capparelli. 20I I. Efectos de la carbonización en especies leñosas de las provincias fitogeográficas Patagónica y del Monte (Mendoza, Argentina): una perspectiva arqueológica. En Traditions and transformations in Ethnobotany, editado por M.L. Pochettino, y A. Ladio., Pp. 33-37. Cyted San Salvador de Jujuy, Argentina.

Badal García, E. 1992. "L’anthracologie préhistorique: à propos de certains problèmes méthodologiques". Bulletin de la Société Botanique de France 139: 167-189.

Cabrera, A. 1959. "Revisión del Genero "Dasyphyllum”. Revista del Museo de La Plata (Nueva Serie) Botánica IX(38):2 I - I00.

Cabrera A. 1976. "Regiones Fitogeográficas Argentinas". Enciclopedia Argentina de Agricultura y Jardinería II(I):347-4I I.

Capitanelli, R. 2005. Climatología de Mendoza. Ed Facultad de Filosofía y Letras. Universidad Nacional de Cuyo. Mendoza, Argentina

Chabal, L. 1988. "Pourquoi et comment prélever les charbons de bois pour la période antique, les méthodes utilisées sur le site de Lattes (Hérault)". Lattara I:187-222.

Chabal, L. 1990. "L'étude paléoécologique des sites protohistoriques à partir des charbons de bois, la question de l'unité de mesure". En Wood and Archaeology, editado por T. Hackens, A.V. Munaut and., C. Till, Pp- I89-205PACT, Louvain la Neuve, Belgique.

Ciampagna M L 2015 Estudio de la interacción entre grupos cazadores recolectores de Patagonia y las plantas silvestres: el caso de la costa norte de Santa Cruz durante el Holoceno medio y tardío. Tesis Doctoral. Facultad de Ciencias Naturales y Museo. UNLP

Cornejo, L. y Sanhueza, L. 2003. “Coexistencia de cazadores recolectores y horticultores tempranos en la cordillera andina de Chile Central". Latin American Antiquity I4(4):389-407.

Cornejo, L. y Sanhueza, L.20I Ia. "North and south: hunter-gartherer communities in the Andes mountains in Central Chile". Latin American Antiquity 22(4):487-504

Cornejo, L. y Sanhueza, L. 20I Ib. "Caminos que cruzan la cordillera: el rol del paso del Maipo en la ocupación de la Cordillera en Chile Central". Revista de Antropología 23(I): I0I-I 22

Darwinion. 20I4. http://www2.darwin.edu.ar/Proyectos/ FloraArgentina

Durán, V., G. Neme, V. Cortegoso y A. Gil. 2006. "Arqueología del Área Natural Protegida Laguna del Diamante (Mendoza,Argentina)". Anales de Arqueología y Etnología 61:8I-134

Garibotti, I.A. 1998. “Análisis de la estructura anatómica de carbones arqueológicos de sitios incaicos (ca. I480-I530 d.C.) del Valle de Uspallata (Mendoza, Argentina)". Boletín de la Sociedad Argentina de Botánica 33 (3-4): 195-205.

Garribotti, I.A. 1999-2000.“Los carbones arqueológicos de sitios incaicos del Valle de Uspallata, Provincia de Mendoza estudio Arqueológico". Xama 12-14:49-60.

Giesso M., V. Durán, G. Neme, M.D. Glascock, V. Cortegoso, A. Gil., L. Sanhueza.20I I. "A study of obsidian source usage in the Central Andes of Argentina and Chile". Archaeometry 53:I-2I.

IAWA 1989."List of microscopic features for hardwood identification”. E. Wheeler, P. Baas \& P. Grason (eds.) IAWA Bulletin 10:219-332.
Inside Wood. 20I3. Disponible en: www.insidewood.lib. ncsu.edu,

Juggins. S. 2007 C2 Versión I.7.2 Software for ecological and palaeoecological data analysis and visualisation. (Disponible en: http://www.staff.ncl.ac.uk/stephen.juggins).

Lagiglia, H. 1975. "Prehistoria del Centro Oeste Argentino". Notas del Museo de Historia Natural de San Rafael I5.

Lagiglia H. 1997. Arqueología de Cazadores-Recolectores Cordilleranos de Altura. Ediciones Ciencias y Arte Instituto de Ciencias Naturales de San Rafael-Mendoza.

Lagiglia, H., A. Gil y G. Neme. 1994."Informe de los trabajos de campo en El Indígeno ( $3^{\circ}$ Campaña arqueológica)". Actas y Memorias del XI Congreso Nacional de Arqueología Argentina (segunda parte) Revista del Museo de Historia Natural de San Rafael Mendoza XIV (I/4): I I6-II8I.

Llano, C. y D.F. Andreoni. 2012. "Caracterización espacial y temporal en el uso de los recursos vegetales entre los grupos cazadores-recolectores del sur mendocino durante el Holoceno" En Paleoecología humana en el sur de Mendoza: perspectivas arqueológicas. Compilado por G. Neme y A. Gil, Pp.5784. Sociedad Argentina de Antropología, Buenos Aires.

Marconetto, M.B. 2005. Recursos forestales y el proceso de diferenciación social en tiempos prehispánicos en el valle de Ambato, Catamarca. Tesis Doctoral Inédita. Facultad de Ciencias Naturales y Museo, Universidad Nacional de La Plata. La Plata.

Muñoz-Schick M., A. Moreira-Muñoz, C. Villagrán y F. Luebert. 2000. "Caracterización florística y pisos de vegetación en los Andes de Santiago, Chile Central". Boletín del Museo Nacional de Historia Natural 49: 9-55.

Neme, G. 2007. Cazadores-Recolectores de Altura en los Andes Meridionales. BAR Series I59I, Reino Unido

Neme, G. y A. Gil 2013. "Ocupaciones de altura en el sur de Mendoza: configuración ambiental y estrategias humanas". Actas del XVII Congreso Nacional de Arqueología, pp: 305. La Rioja, Argentina.

Pique í Huerta, R. 1999. Producción y uso de combustible vegetal arqueológico: Una evaluación arqueológica. Treballs d`Etnoarqueología $N^{\circ} 3$. Universidad Autónoma de Barcelona, Madrid.

Rancusi, M.H., M. Nishida y H. Nishida. 1987. "Xilotomy of Important Chilean Woods". En Contributions to the Botany in the Andes II, editado por M. Nishida, Pp. 68-I58. Academy Scientifi Book, Tokio.

Rallo, M., D. Montecinos, T. Mundaca. 2008. "Perforaciones escalariformes en vasos de árboles nativos de Chile". Maderas Ciencias y Tecnología I0(2):I63-I72.

Rivera, S. 1988. "Revisión xilológica del género Nothofagus BL (Fagaceas) para la Argentina Simposio de Nothofafus". Monografias de la Academia Nacional de Ciencias Exactas, Físicas y Naturales 4:73-84

Roig, FA. y R. Bárcena. 1997. “Identificación anatómica de maderas actuales y carbones arqueológicos del área del Tambo Incaico de Tambillos (Uspallata), Mendoza, Argentina”. Parodiana 10:91-112.

Ruiz Leal, A. 1972. Flora Popular Mendocina. Deserta III. Contribuciones del Instituto Argentino de Zonas Áridas, Mendoza.

Sanhueza, L., F. Falabella, E. Fonseca, 0. Andonie. 2004. "Aplicación de análisis de pastas macroscópicos, 
petrográficos y de composición de elementos químicos al problema de la procedencia de cerámica en el Período Alfarero Temprano de Chile Central y Cuyo, Argentina”. Estudios Atacameños 28:121-132.

Smart, T. y E. Hoffman 1988. "Environmental interpretation of archaeological charcoal". En Current Palaeoethnobotany: analytical methods and cultural interpretations of archaeological plant remains, editado por Hastorf C.A.y V.S. Popper, Pp. 167-205.The University of Chicago Press, Chicago and London.

Solari, M.E. 1993. L'homme et le bois en Patagonie et Terre de Feu au cours des six deniers millénaires: recherches anthracologiques au Chili et en Argentine. Tesis Doctoral Inédita. Universidad de Montpellier, sede II, Francia

Thiébault, S. 1989. “Apport de l’analyse anthracologique à la connaissance des combustibles ligneux". En: Nature et fonction des foyers préhistoriques, editado por Olive M. y Y. Taborin, Pp. 8I86. Colloque Internacional de Némours.

Tortorelli L.A. 2009. Maderas y Bosques Argentinos. $2^{\circ}$ Edición. Orientación gráfica, Buenos Aires.

Zapata, L. y I. Figueiral. 2003. "Carbones y semillas en los yacimientos dolménicos, posibilidades y límites del análisis arqueobotánico". En La Recogida de Muestras en Arqueobotánica: Objetivos y Propuestas Metodológicas. Compilado por R. Buxó y R. Piquéi Huerta, Pp. 55-65. Museu d' Arqueologia de Catalunya, Barcelona. 